\title{
Indoor microbiota in severely moisture damaged homes and the impact of interventions
}

Balamuralikrishna Jayaprakash ${ }^{1 \dagger}$, Rachel I. Adams ${ }^{2,3 \dagger}$, Pirkka Kirjavainen ${ }^{1}$, Anne Karvonen ${ }^{1}$, Asko Vepsäläinen ${ }^{1}$, Maria Valkonen ${ }^{1}$, Kati Järvi ${ }^{4}$, Michael Sulyok ${ }^{5}$, Juha Pekkanen ${ }^{1,6}$, Anne Hyvärinen ${ }^{1}$ and Martin Täubel ${ }^{1 *}$ (D)

\begin{abstract}
Background: The limited understanding of microbial characteristics in moisture-damaged buildings impedes efforts to clarify which adverse health effects in the occupants are associated with the damage and to develop effective building intervention strategies. The objectives of this current study were (i) to characterize fungal and bacterial microbiota in house dust of severely moisture-damaged residences, (ii) to identify microbial taxa associated with moisture damage renovations, and (iii) to test whether the associations between the identified taxa and moisture damage are replicable in another cohort of homes. We applied bacterial 165 rRNA gene and fungal ITS amplicon sequencing complemented with quantitative PCR and chemical-analytical approaches to samples of house dust, and also performed traditional cultivation of bacteria and fungi from building material samples.
\end{abstract}

Results: Active microbial growth on building materials had significant though small influence on the house dust bacterial and fungal communities. Moisture damage interventions-including actual renovation of damaged homes and cases where families moved to another home-had only a subtle effect on bacterial community structure, seen as shifts in abundance weighted bacterial profiles after intervention. While bacterial and fungal species richness were reduced in homes that were renovated, they were not reduced for families that moved houses. Using different discriminant analysis tools, we were able identify taxa that were significantly reduced in relative abundance during renovation of moisture damage. For bacteria, the majority of candidates belonged to different families within the Actinomycetales order. Results for fungi were overall less consistent. A replication study in approximately 400 homes highlighted some of the identified taxa, confirming associations with observations of moisture damage and mold.

Conclusions: The present study is one of the first studies to analyze changes in microbiota due to moisture damage interventions using high-throughput sequencing. Our results suggest that effects of moisture damage and moisture damage interventions may appear as changes in the abundance of individual, less common, and especially bacterial taxa, rather than in overall community structure.

Keywords: Indoor, Built environment, Moisture damage, Dampness, Indoor mold, Intervention, House dust microbiota, Amplicon sequencing

\footnotetext{
* Correspondence: martin.taubel@thl.fi

${ }^{\dagger}$ Equal contributors

${ }^{1}$ Environmental Health Unit, National Institute for Health and Welfare, Kuopio,

Finland

Full list of author information is available at the end of the article
} 


\section{Background}

Living and working in buildings that are affected by moisture damage and dampness has been associated with adverse health outcomes, specifically respiratory symptoms and infections, and exacerbation and new onset of asthma. The epidemiological evidence supporting these associations is sound and has been reviewed and evaluated repeatedly [1-4]. A causal connection between moisture damage and the exacerbation of asthma has been recently proposed [5]. The actual causative agents and the mechanisms underlying these associations are unknown.

A multitude of exposing agents may be increased by moisture in buildings. These include biological and chemical factors, such as fungal and bacterial spores and fragments, their metabolites and mycotoxins, as well as volatile organic compounds emitted from damp building materials and structures or being produced during microbial growth [3]. Of these, exposure to microbes and their structural components and metabolites are thought to be a key contributor to adverse health effects observed in occupants of damp buildings. Moisture damage and dampness in buildings is linked to microbial growth on building materials [6-9]. Qualitative and quantitative changes in fungal and bacterial exposures in indoor air and dust in response to moisture problems have been reported repeatedly [10-17], but other studies did not find clear associations [18-21]. Studies investigating the role of microbes in the association between moisture damage and adverse health are less conclusive and have produced little consistent and often contradictory results. Both positive and negative associations, as well as the absence of an association of microbial exposure in moisture damage buildings with respiratory symptoms and clinical measurements have been reported [4, 22-26]. It is apparent that not only quantitative but also qualitative aspects of the exposure in damp buildings may be relevant, defining the needs for exposure assessment methods towards increasing the resolution to better define the qualitative content of the microbial exposure.

Our current understanding of moisture-related changes in the indoor microbiota largely relies on studies using traditional cultivation-based fungal and bacterial measurements. This work has culminated in proposing fungal and bacterial taxa which-when present in indoor air or on building materials-may indicate moisture damage and dampness problems in a building [6]. Quantitative PCR (qPCR) was introduced to the field almost two decades ago [27] and is widely used today [28, 29]. However, a limitation in qPCR-based approaches is that the target taxa are largely based on knowledge from cultivation studies.

High throughput sequencing approaches have been applied to indoor environments to improve our understanding of the microbial ecology in buildings and to ultimately assess health implications of exposure to the indoor microbiome. Only few of these sequencing studies have addressed at least to some extent the effect of moisture damage and indoor dampness on indoor microbiota [12, 30-35], and to date there are no clear patterns of microbial response to water damage.

There is need for dedicated studies that would generate new information on microbial signatures of moisture damage, utilizing microbial exposure data with high resolution. In our current study we aimed to (i) characterize fungal and bacterial microbiota in the house dust of severely moisture-damaged residential homes, (ii) identify microbial signatures of moisture damage by following homes through moisture damage renovations, and (iii) test whether the associations of the identified taxa with moisture damage are replicable in a large cohort of residential homes with varying degrees of observed moisture damage and visible mold.

\section{Methods \\ Study population}

The HOTES study (HOmeloukku ja TErveysSeuranta- "moldy homes and health study") was conducted in severely moisture-damaged homes across Finland and among their occupants. HOTES is an intervention study with the main focus on the effects of moisture damage and moisture damage interventions on occupant exposure and health. In this current report, we focus on the microbial changes during moisture damage interventions; the health outcomes in this study will be analyzed and reported separately. Families contacted the Organization for Respiratory Health (Hengitysliitto, Finland) and requested help in assessing their homes because of possible moisture damage. Once a civil engineer visited the homes and verified severe moisture damage requiring an intervention, the occupants and their homes were recruited to the study. All participating homes were single-family houses and were located mainly in the central and eastern parts of Finland.

From 2008 to 2013, 41 severely damaged houses and their occupants were recruited to this study and preintervention exposure samples were collected. Of these 41 homes, a total of 20 homes were also examined postinterventions, with exposure and health assessments conducted the same way as pre-intervention, and paired pre and post house dust samples were used for the current analyses (Table 1). Homes that underwent an intervention compared to homes that did not, had more occupants and higher number of toxins detectable from house dust; no significant differences were observed for the other key environmental and microbial variables (levels of Gram-positive and Gram-negative bacteria, total fungi and FERMI index, and viable bacteria and fungi detected from building material samples; prevalence of pet 
Table 1 Study populations used in the analyses, numbers of homes, and number of samples

\begin{tabular}{|c|c|c|c|}
\hline & \multirow[t]{2}{*}{$\begin{array}{l}\text { Moisture-damaged } \\
\text { homes }\end{array}$} & \multicolumn{2}{|c|}{$\begin{array}{l}\text { Moisture damage intervention } \\
\text { populations }\end{array}$} \\
\hline & & $\begin{array}{l}\text { Moisture damage } \\
\text { renovations }\end{array}$ & $\begin{array}{l}\text { Moved to a } \\
\text { newly built or } \\
\text { existing house }\end{array}$ \\
\hline $\begin{array}{l}\text { Number of } \\
\text { homes }\end{array}$ & 41 & 9 & 11 \\
\hline \multicolumn{4}{|c|}{ Number of samples } \\
\hline $\begin{array}{l}\text { Floor dust } \\
\text { living room } \\
\text { (FDLR) }\end{array}$ & 40 & 8 & 11 \\
\hline $\begin{array}{l}\text { Floor dust } \\
\text { other room } \\
\text { (FDOR) }\end{array}$ & 24 & 4 & 1 \\
\hline $\begin{array}{l}\text { Airborne } \\
\text { settled dust } \\
\text { (SD) }\end{array}$ & 37 & 8 & 9 \\
\hline $\begin{array}{l}\text { Total house } \\
\text { dust samples }\end{array}$ & 101 & 20 & 21 \\
\hline
\end{tabular}

keeping, living in a farming environment, urban versus rural location of the home, and season of dust sampling). Of those 20 homes, nine underwent a moisture damage renovation where the families remained in the same home following building repair (referred to here as "renovated"), eight families moved into an existing home, and three families built a new home. In our analyses, homes where families moved into an existing or a newly built home were combined and referred to as "moved."

\section{Building inspections and determination of viable fungi and bacteria from building material samples}

Information on building structures, history, materials and moisture damage was received from the technical investigation and interview that was performed by civil engineers with the Organization for Respiratory Health. The civil engineers took building material samples from damaged locations before the renovation to confirm microbial growth in the building structures, where that was deemed necessary. Through cultivation, viable counts and composition of microbes were determined from building material samples, as described earlier [7]. Two fungal media, 2\% malt extract agar (MEA) and dichloranglycerol 18- agar (DG18) with chloramphenicol, and one bacterial medium, tryptone yeast glucose agar (TYG) with natamycin, were used. These are commonly used and broad media for the detection of fungi and bacteria in indoor environments. MEA favors growth of hydrophilic fungi, while DG18 is more suitable for growth of xerophilic fungi [6]. The total concentration of viable fungi was based on the higher value observed in the two fungal media (MEA or DG18). The categorization of homes based on fungal and bacterial colony counts from building materials has been described elsewhere (Järvi et al., manuscript submitted). In brief, median values of viable counts of fungi and bacteria were calculated for each of the homes from all of the building material samples taken from living areas of the homes, including living rooms, bedrooms, and kitchens based on the assumption that most exposure happens in these rooms.

\section{House dust sampling for microbial determinations}

House dust samples, representing integrated exposure over time, were collected with protocols developed and applied in previous studies [36]. Floor dust sample was obtained by attaching a nylon sample sock to a vacuum cleaner's pipe and by vacuuming a floor area (preferably rugs) of $5 \mathrm{~m}^{2}$ for $10 \mathrm{~min}$ in the living room (FDLR). For homes where major moisture-damaged areas were observed outside the living room, vacuumed floor dust samples were collected from these other areas (FDOR). A settled dust sample (SD) was vacuumed with the same method from elevated areas above floor level, e.g., from the top of cupboards or shelves $\left(1-2 \mathrm{~m}^{2}\right.$ sampling area, typically; $10 \mathrm{~min}$ vacuuming). The floor dust samples were homogenized by sieving through a sterile strainer, and all samples were dried in a desiccator, aliquoted, and stored at $-20{ }^{\circ} \mathrm{C}$ until DNA extraction.

\section{DNA extraction}

DNA was extracted from approximately $20 \mathrm{mg}$ of house dust that was accurately weighted into $2-\mathrm{mL}$ tubes with glass beads, starting with a bead-milling step for mechanical cell disruption [37], using MiniBeadbeater-16 for 1 min (Biospec Products Inc., USA). DNA was extracted and cleaned from the samples using the Chemagic DNA Plant-kit (PerkinElmer chemagen Technologie GmbG, Germany) and KingFisher mL DNA extraction robot (Thermo Scientific, Finland). $0.64 \mu \mathrm{g}$ of deoxyribonucleic acid sodium salt from salmon testes (Sigma Aldrich Co., USA) [38] was added to the samples prior to extraction as an internal standard, in order to assess and correct for the presence of inhibitors and the performance of the DNA extraction. DNA was stored at $-20{ }^{\circ} \mathrm{C}$ until subsequent analysis. Negative (reagents) and positive (bacterial and fungal mock community) controls were included in the DNA extraction step along with house dust samples.

\section{Quantitative PCR analysis}

Quantitative PCR (qPCR) was used for quantitation of fungal and bacterial biomass using previously published qPCR assays: Gram-positive and Gram-negative bacteria groups [37], and total fungal DNA [28]. QPCR analyses of the fungal species included those used for calculation of the Finnish Environmental Relative Moldiness Index (FERMI) [39] and were performed as previously described 
[28]. The FERMI index is a quantitative-based assessment of different types of fungi indoors modeled after ERMI [29]. QPCR analysis of the internal standard salmon testis DNA followed the instructions by Haugland et al. [38]. In the bacterial duplex assay (Gram-positive and negative bacteria), $20 \mu \mathrm{l}$ reaction mix were used, consisting of $10 \mu \mathrm{l}$ of Environmental Master Mix (Applied Biosystems Inc., Foster City, CA), $1.5 \mu \mathrm{l}$ bovine serum albumin $(2 \mathrm{mg} / \mathrm{ml})$, $500 \mathrm{nM}$ forward and reverse primers and $200 \mathrm{nM}$ each of the two TaqMan probes, $3.7 \mu \mathrm{l}$ of nuclease-free water (HyClone Laboratories Inc., Utah, USA), and finally $2 \mu \mathrm{l}$ of template DNA. Reactions were performed in $0.2-\mathrm{ml}$ 96-well plates (Agilent Technologies Inc., USA) for Stratagene Mx3005P QPCR System (Agilent Technologies Inc., USA) equipment. Numbers of microbial cell equivalents in the samples were calculated using relative quantification [40] and presented as detected microbial cell equivalent per milligram dust.

\section{Determination of microbial toxins}

A 50-mg subsample of dust was used for the secondary metabolite analysis. Metabolites were extracted and diluted from dust using acetonitrile/water/acetic acid solution. The analysis was performed as described earlier [41] but with an expanded range of detectable microbial secondary metabolites (348 fungal and 44 bacterial metabolites) and a more sensitive LC-MS/MS system. In brief, we used Agilent 1290 Series HPLC System (Agilent, Waldbronn, Germany) coupled to a QTrap 5500 equipped with Turbo Ion Spray ESI source (Applied Biosystems, Foster City, CA, USA) in connection with a Gemini ${ }^{\circ} \mathrm{C} 18$ column, $150 \times 4.6 \mathrm{~mm}$ i.d., $5 \mu \mathrm{m}$ particle size protected by a $\mathrm{C} 18$ security guard cartridge, $4 \times 3 \mathrm{~mm}$ i.d. (all from Phenomenex, Torrance, CA, USA). A methanol/water gradient containing $1 \%$ acetic acid and $5 \mathrm{mM} \mathrm{NH} 4 \mathrm{Ac}$ was used at $1 \mathrm{ml} / \mathrm{min}$. Data acquisition was performed in the scheduled multiple reaction monitoring (sMRM) mode in both positive and negative polarity using two separate chromographic runs per sample. Confirmation of the identity of the investigated analytes was obtained through acquiring two sMRM transitions (except for moniliformin and 3-nitropropionic acid, which yield only one detectable fragment ion) and comparison of the intensity ratio and LC retention time to an authentic standard. Quantification was performed based on linear, $1 / x$ weighed calibration curves deriving from serial dilutions of a multi-analyte standard.

\section{DNA sequencing}

The DNA extracted from house dust and control samples was shipped frozen to the sequencing service partner LGC Genomics (Germany), who did the library preparation and sequencing. For bacteria, a preamplification of sample DNA was performed using primers 341F (CCTACGGGNGGCWGCAG) [42] and 1061R (CRRCACGAGCTGACGAC) [43]. The PCRs included approximately $5 \mathrm{ng}$ of DNA extract, $15 \mathrm{pmol}$ of each primer in $20 \mu \mathrm{l}$ volume of MyTaq buffer containing 1.5 units MyTaq DNA polymerase (Bioline $\mathrm{GmbH}$, Luckenwalde, Germany), and $2 \mu \mathrm{l}$ of BioStabII PCR Enhancer (Sigma-Aldrich Co.). Pre-amplification PCRs were carried out for 20 cycles using the following parameters: 2 min $96{ }^{\circ} \mathrm{C}$ predenaturation; $96{ }^{\circ} \mathrm{C}$ denaturation for $15 \mathrm{~s}, 50{ }^{\circ} \mathrm{C}$ annealing for $30 \mathrm{~s}, 70{ }^{\circ} \mathrm{C}$ extension for $90 \mathrm{~s}$, hold at $8{ }^{\circ} \mathrm{C}$. The V4 region of the $16 \mathrm{~S}$ rRNA gene was amplified using 515F/806R primers for $20 \mathrm{cy}$ cles [44]. For fungi, the ITS1 region of the Internal Transcribed Spacer (ITS) was amplified using ITS1F/ ITS2 primers and 33 cycles [45].

The PCRs included either approximately 5 ng of DNA extract (for fungi), or $1 \mu \mathrm{l}$ pre-amplification product (for bacteria), 15 pmol of each forward primer $515 \mathrm{~F} \mathrm{~N}_{1-}$ ${ }_{10}$ GTGCCAGCMGCCGCGGTAA and reverse primer 806R N $\mathrm{N}_{1-10}$ GGACTACHVGGGTWTCTAAT, ITS1F $\mathrm{N}_{1-}$ ${ }_{10}$ CTTGGTCATTTAGAGGAAGTAA and ITS2 $\mathrm{N}_{1-}$ ${ }_{10}$ GCTGCGTTCTTCATCGATGC $\left(\mathrm{N}_{1-10}\right.$ indicate the 10 nucleotide inline-barcodes), in $20 \mu \mathrm{l}$ volume of MyTaq buffer containing 1.5 units MyTaq DNA polymerase (Bioline $\mathrm{GmbH}$, Luckenwalde, Germany) and $2 \mu \mathrm{l}$ of BioStabII PCR Enhancer (Sigma-Aldrich Co.). For each sample, the forward and reverse primers had the same 10-nt barcode sequence. PCRs were carried out for either 33 cycles (ITS-PCR on DNA extract) or 20 cycles (16 s-PCR on pre-amplification product) using the following parameters: 2 min $96{ }^{\circ} \mathrm{C}$ predenaturation; $96{ }^{\circ} \mathrm{C}$ denaturation for $15 \mathrm{~s}, 50{ }^{\circ} \mathrm{C}$ annealing for $30 \mathrm{~s}$, $70{ }^{\circ} \mathrm{C}$ extension for $90 \mathrm{~s}$, hold at $8{ }^{\circ} \mathrm{C}$. About $20 \mathrm{ng}$ amplicon DNA of each sample were pooled for up to 48 samples carrying different barcodes. PCRs showing low yields were further amplified for 5 cycles. The amplicon pools were purified with one volume Agencourt AMPure XP beads (Beckman Coulter, Inc., IN, USA) to remove primer dimer and other small mispriming products, followed by an additional purification on MinElute columns (QIAGEN GmbH, Hilden, Germany). About $100 \mathrm{ng}$ of each purified amplicon pool DNA was used to construct Illumina libraries using the Ovation ${ }^{\circ}$ Rapid DR Multiplex System 1-96 (NuGEN Technologies, Inc., CA, USA). Illumina libraries (Illumina, Inc., CA, USA) were pooled and size selected by preparative gel-electrophoresis.

Sequencing was performed on an Illumina MiSeq with V3 chemistry resulting in paired-end reads with a length of $300 \mathrm{bp}$ each. The libraries were demultiplexed using Illumina's bcl2fastq v1.8.4 (https://support.illumina.com/ downloads/bcl2fastq_conversion_software_184.html) and all sequence reads processed with custom Python v2.7.6 scripts to sort them by sample, removing barcode and amplicon primer sequences. Adapter sequences were 
removed from the $3^{\prime}$ end of reads with a proprietary script discarding reads shorter than $100 \mathrm{bp}$.

\section{Bioinformatic analysis}

All 16S rRNA gene and ITS-targeted amplicon reads were processed and analyzed using QIIME (Quantitative Insights Into Microbial Ecology) software version 1.9.1 [46]. The raw bacterial reads were preprocessed by removal of artificial sequences such as adapters by cutadapt software [47], followed by trimming of bad quality reads and ambiguous sequences by the Trimmomatic software [48]. Then, the preprocessed reads were merged using FLASH (Fast Length Adjustment of SHort reads) software [49]. UCHIME [50] was employed to remove chimeras in the preprocessed reads using the USEARCH algorithm [51]. After chimera removal, the preprocessed reads were aligned using pynast [52] with the Greengenes database [53] and sorted with $>97 \%$ similarity into operational taxonomic units (OTUs) using open reference OTU picking approach for bacteria. For fungi, the data processing was similar until the chimera removal step. We used FHiTINGS (Fungal High throughput Taxonomy Identification in NGS) to calculate taxa-based OTU groups instead of clustering [54]. Negative and positive (bacterial and fungal mock) controls were included in the sequence processing of the samples in order to inform estimates of alpha richness in the samples and to exclude samples closely clustering to control samples in PCoA plots. Alpha rarefaction was done at 2700 sequences for bacteria and at 737 sequences for fungi. Taxonomic classification was obtained using the RDP classifier [55] for bacteria and FHiTINGS for fungi. Alpha-diversity values were calculated in QIIME using Chao1, Simpson, and Shannon; beta-diversity values were calculated using Unifrac distance metric for bacteria [56] and the Bray-Curtis and Binary Jaccard metrics for fungal analyses. Emperor was used to visualize the beta diversity plots. The NMDS plot was done with the ggplot2 package [57] from $\mathrm{R}$ Version 3.0.2 [58] to display the beta-diversity differences between the samples.

A phylogenetic tree was constructed with the 3719 bacterial OTUs identified. The sequences for the OTUs were obtained from the Greengenes database and the phylogenetic tree was constructed using the Neighbor joining algorithm within the MEGA7 software [59].

\section{Replication study in the LUKAS cohort}

Details on the LUKAS cohort, the dust sampling and sample processing, sequencing and sequence processing are provided in the Supplement (Additional file 1). In brief, the LUKAS study is a birth cohort that consists of 442 single family homes in eastern and middle Finland with approximately one fourth of the homes being farming homes [60]. Floor dust sampling and standardized home inspections were performed in early life of the participating study children, providing classification on moisture damage (no, minor, major) and visible mold (no, mold spots, visible mold) for the current analyses. Dust processing, DNA extraction, PCR and bacterial 16S rRNA gene and fungal ITS1 amplicon sequencing, sequence processing, and bioinformatics were similar between the HOTES and LUKAS datasets. More detail on the cohort, dust sampling, and sequencing is provided in Additional file 1, Supplement text.

\section{Statistical analyses \\ Impact of environmental and microbial factors on community composition}

We used the ANOSIM statistical test available in QIIME to study associations of environmental factors with other microbial measurements, as well as the impact of moisture damage interventions on microbial community composition. Bacterial weighted and unweighted Unifrac distance and fungal Bray-Curtis and Binary Jaccard distance metrics were used to define bacterial and fungal beta-diversity. qPCR biomass determinations (Grampositive and Gram-negative bacteria, total fungi), FERMI index, and number of detected microbial secondary metabolites were categorized into tertiles for the analyses on associations with bacterial and fungal beta-diversity. For the analyses against viable bacterial and fungal growth on building materials, pre-intervention study homes were divided into three approximate equal sized groups-low, moderate, high bacterial/fungal viable growth-based on median values derived from total viable bacterial and fungal counts in cultivation of building material samples in these homes. Pet keeping was defined as any number of dogs and/or cats. Other home environmental determinants tested were the season of sampling and urban versus rural location of the study home (the metadata file used in these analyses is supplemented in Additional file 2, Table S1).

\section{Impact of interventions on alpha-diversity and top abundant taxa}

The impact of moisture damage interventions-for all interventions combined and for "renovation" and "families moved" separately-on Chao1 estimated richness, Shannon diversity index, and the 15 most abundant bacterial and fungal genera (selected based on their median prevalence in samples pre intervention) were done in pairwise comparisons of samples taken in the same locations pre and post intervention (information on the paired sample codes is provided in Additional file 2, Table S2). Non-parametric statistical methods were used because outcomes were not normally distributed. The differences between pre and post were tested using Wilcoxon signed-rank test (for matched pair data) 
using SAS software (version 9.3, SAS Institute Inc., Cary, NC, USA).

\section{Identification of indicator taxa}

We used three different approaches in an attempt to identify bacterial and fungal indicator taxa associated with moisture damage renovations. Approach 1 is a community structure-based approach, identifying principal coordinates from the community distance metrics with associations to the outcome of interest and selecting those taxa correlating strongest with these coordinates; approach 2 is a commonly used tool for biomarker discovery, however, not allowing for adjustment of potential confounders, which approach 3 adds to the analyses.

In approach 1, we first used the principal coordinate (PC) scores derived from bacterial weighted and unweighted Unifrac distance and fungal Bray-Curtis and Binary Jaccard distance metrics. We considered PCs with Eigenvalue $>1$ for the analysis. Associations of the selected PCs with moisture damage interventions-performed separately for "renovation" and "families moved"-were analyzed using pairwise Wilcoxon signed-rank test as described above for alpha-diversity. PCs with significant associations $(p<0.05)$ were selected and Spearman rankorder correlations estimated with the relative abundance of all bacterial OTUs and fungal taxa in the sample. Correlation scores $>|0.5|$ for bacterial and $>|0.4|$ for fungal taxa were used as criteria to select the taxa for subsequent indicator analyses.

In approach 2, we applied LEfSe version 1.0.7 [61], which is a biomarker discovery tool based on linear discriminant analysis. LEfSe is a three-step algorithm that lists differential features with statistical and biological significance (LDA effect size). Here, we applied LEfSe to compare relative abundance of bacterial OTUs and fungal taxa in pre versus post renovation comparisons of house dust samples and to identify discriminative features. We used standard criteria of significance $<0.05$ and LDA effect size $>2$ to include identified taxa for subsequent analyses.

Finally, in approach 3, we applied edgeR (glm-edgeR) [62]. edgeR is a tool that has been developed for differential gene expression analysis and gene marker identification based on generalized linear model and probability distribution model fitting. The function glm-edgeR() has inbuilt false discovery rate (FDR) correction to provide corrected $p$ values in the final results. Here, we use EdgeR on bacterial and fungal taxa instead of genes with the aim to identify microbial markers associated with moisture damage renovation. The analyses were adjusted for the potential confounders: sample type, season, pet keeping, urban and rural location of the home, and the number of occupants. We used a cut-off of FDR corrected $p$ values $<0.1$ for inclusion of taxa for further studies.
Results from approaches 1-3 were considered together. Bacterial OTUs that were identified by at least two methods and fungal taxa that were identified by any one method were considered potential indicator taxa and tested pre versus post comparisons for "renovation" and "families moved" in pairwise Wilcoxon signed-rank test.

\section{Replication study in the LUKAS cohort}

Kruskal-Wallis test with Bonferroni correction for testing multiple candidate OTUs was used to study whether the OTUs associated with moisture damage in HOTES were found in higher levels in LUKAS homes with than without moisture damage or visible mold. The independence of significant differences of potential confounders (LUKAS cohort, type of living area (rural farm, rural non-farm, suburban), construction year of the house, building type (single family house, others), heating (central water-heating, electric heating), and season of dust collection (fall, winter, spring, summer) were tested with quantile regression using 200 permutations to obtain $95 \%$ confidence intervals.

\section{Results \\ Microbiota of different types of house dust in moisture-damaged homes}

Sample type, i.e., floor dust (FDLR) versus settled dust (SD), had a small but significant impact on both bacterial $(R=0.054 ; p=0.01)$ and fungal $(R=0.096 ; p=0.001)$ abundance weighted communities in ANOSIM analyses, and we therefore explored the effects of moisture damage separately for living room floor and airborne settled dust (detailed below). The mean relative abundances of the most prominent bacterial and fungal genera in the different sample types are presented in Additional file 1 (supplemental text) and Additional file 3: Figures S1A and S1B. Bacterial and fungal alpha-diversity estimates (Chao1 estimates richness, Shannon index) were not significantly different between the different sample types (Additional file 2: Table S3).

We evaluated associations of environmental variables and other microbial measurements on the beta-diversity of bacterial and fungal microbiota in house dust of moisture-damaged homes. Table 2 presents results based on ANOSIM analyses using weighted bacterial Unifrac and fungal Bray-Curtis distance-based calculations. The results for using both weighted and unweighted bacterial and fungal distance matrices are detailed in Additional file 2: Tables S4 and S5). Overall, effect sizes ( $R$ value) were small. Household environmental characteristics more strongly influenced fungi than bacteria in homes. Urban versus rural location of the home showed a statistically significant but small overall impact for fungal microbiota in the settled dust (Table 2). The season of sampling also had an impact on fungal communities in the floor dust (Table 2), as 
Table 2 Impact of home environmental and microbial measurement parameters on the composition of the bacterial and fungal microbiota in severely moisture-damaged homes. ANOSIM analysis used weighted Unifrac distance for bacteria and fungal BrayCurtis distance (FDLR, floor dust living room; SD, settled dust)

\begin{tabular}{|c|c|c|c|c|c|c|c|c|c|c|c|c|}
\hline \multirow[b]{3}{*}{ Variable tested } & \multicolumn{6}{|c|}{ Bacterial weighted Unifrac } & \multicolumn{6}{|c|}{ Fungal Bray-Curtis } \\
\hline & \multicolumn{3}{|c|}{$\overline{F D L R}$} & \multicolumn{3}{|l|}{ SD } & \multicolumn{3}{|c|}{ FDLR } & \multicolumn{3}{|l|}{ SD } \\
\hline & $N$ & $R$ & $p$ value & $\bar{N}$ & $R$ & $p$ value & $\bar{N}$ & $R$ & $p$ value & $\bar{N}$ & $R$ & $p$ value \\
\hline \multicolumn{13}{|l|}{ Environmental determinants } \\
\hline Pets & 38 & 0.020 & 0.221 & 35 & -0.003 & 0.466 & 38 & -0.050 & 0.985 & 34 & 0.043 & 0.115 \\
\hline Season of sampling & 39 & 0.014 & 0.348 & 34 & -0.012 & 0.587 & 39 & 0.205 & 0.001 & 33 & 0.049 & 0.142 \\
\hline Urban vs. rural & 40 & -0.119 & 0.971 & 36 & 0.105 & 0.108 & 40 & 0.128 & 0.067 & 35 & 0.162 & 0.018 \\
\hline \multicolumn{13}{|l|}{ Biomass-qPCRs } \\
\hline Total fungi & 39 & 0.052 & 0.205 & 34 & 0.017 & 0.330 & 39 & -0.012 & 0.529 & 33 & -0.014 & 0.550 \\
\hline Gram-negative bacteria & 39 & -0.008 & 0.567 & 34 & -0.009 & 0.518 & 39 & -0.046 & 0.828 & 33 & 0.038 & 0.266 \\
\hline Gram-positive bacteria & 39 & -0.047 & 0.807 & 34 & 0.050 & 0.189 & 39 & -0.047 & 0.792 & 33 & -0.020 & 0.560 \\
\hline FERMI qPCR index & 39 & 0.117 & 0.035 & 34 & $<0.001$ & 0.444 & 39 & 0.098 & 0.054 & 33 & 0.026 & 0.315 \\
\hline \multicolumn{13}{|l|}{ Microbial secondary metabolites } \\
\hline Number of microbial "toxins" & 39 & 0.054 & 0.163 & 28 & -0.056 & 0.776 & 39 & 0.034 & 0.273 & 28 & -0.050 & 0.733 \\
\hline \multicolumn{13}{|l|}{ Viable microbes in BM } \\
\hline Bacterial growth in BM & 36 & -0.053 & 0.702 & 31 & 0.352 & 0.004 & 36 & 0.000 & 0.467 & 30 & 0.007 & 0.483 \\
\hline Fungal growth in BM & 36 & -0.023 & 0.665 & 31 & -0.042 & 0.827 & 36 & 0.090 & 0.035 & 30 & 0.150 & 0.010 \\
\hline
\end{tabular}

Significant $p$-values $<0.05$ are shown in italics

well as on the bacterial unweighted Unifrac distance (Additional file 2: Table S4). Interestingly, pet keeping appeared not to affect house dust microbiota in this study population.

We also compared other microbial measurements with the sequence-based community approach, and as a whole found modest links between them. Categorized groups of total fungal and bacterial biomass (determined with qPCR) and number of different microbial secondary metabolites (determined with LC-MS/MS) did not have significant impact on either bacterial or fungal communities (Table 2). However, the Finnish Relative Moldiness Index [39] correlated significantly with the bacterial and borderline significantly with the fungal microbiota in floor dust. Notably, the severity of bacterial and fungal growth in the study homes-determined as viable microbial counts from building material samples-was linked to the bacterial and fungal microbiota in house dust (Table 2). That is, those homes that had different levels of microbial growth on building materials (high/ medium/low) tended to have different microbial community composition, although the data do show noise around this trend (Additional file 4: Figure S2).

\section{The impact of moisture damage interventions on house dust microbiota}

We followed 20 homes/families through moisture damage interventions, which in nine homes involved remediation of the moisture damages in the course of renovations, and in the case of 11 homes, families moved (Table 1). We monitored the impact of the interventions in pre versus post comparisons in these 20 homes, in terms of the numbers and types of bacterial and fungal taxa, in order to investigate how interventions changed potential microbial exposures.

In pairwise sample comparisons (pre versus post interventions) of the relative abundance of the 15 top most abundant bacterial and fungal genera in the house dust samples, we found little significant changes (Fig. 1). For bacteria, we observe significant increases in the relative abundance of Staphylococcus after moisture damage renovations, and of Staphylococcus, Streptococcus, and Planococcaceae genera in house dust after families had moved to a new home. For fungi, we found significant decreases for Phoma, Bortrytis, and Monographella genera during moisture damage renovations and significant increase of Davidiella, Sporobolomyces, and Alternaria when people moved to another home.

We observed a significant reduction in the Chao1estimated richness of both bacterial and fungal taxa in house dust for moisture damage renovations. We did not observe a similar reduction in microbial richness in the cases where families moved (Fig. 2). Results were similar when considering Shannon diversity index (Additional file 2: Table S6).

Moisture damage intervention had only a very subtle ( $R$ values below 0.1 ) though significant impact on the bacterial community composition when measured by 

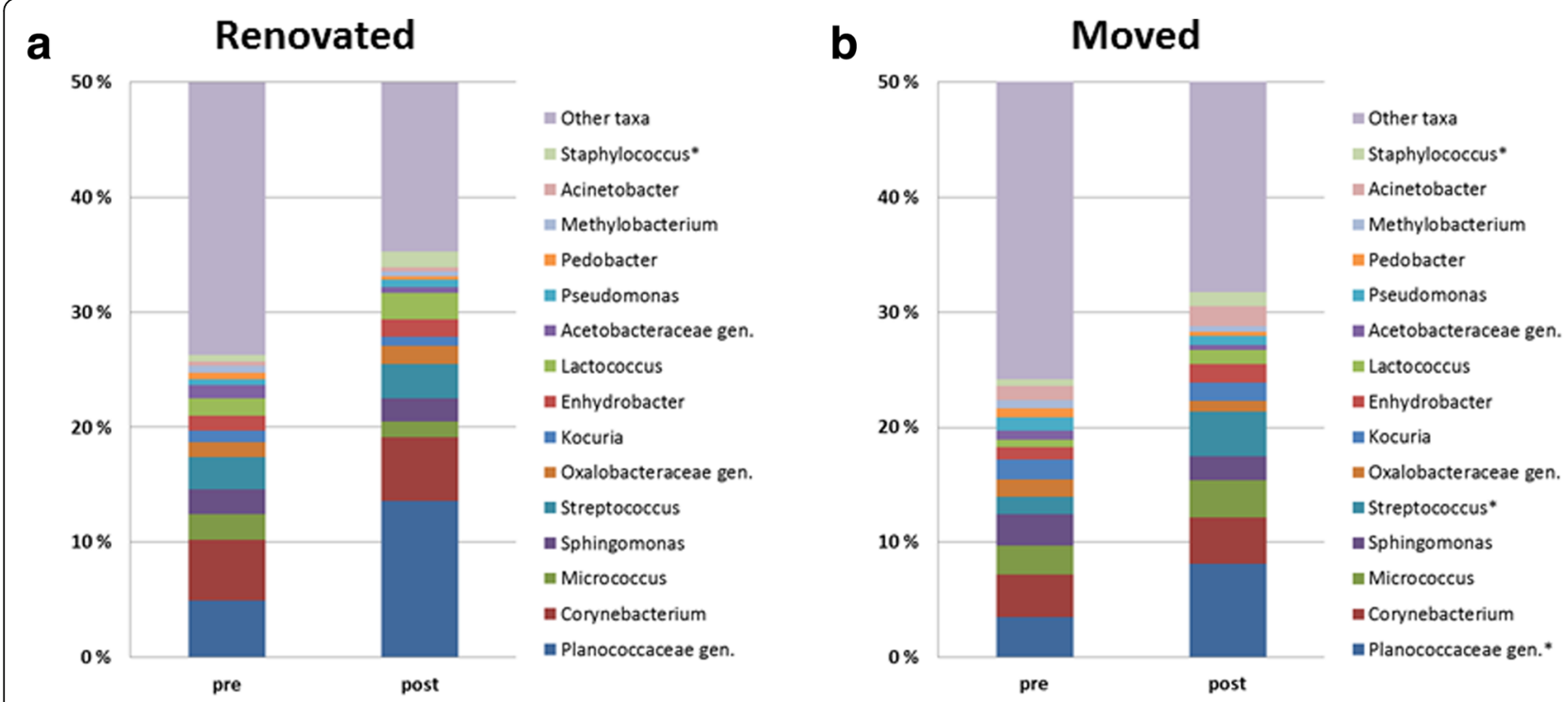

C

d
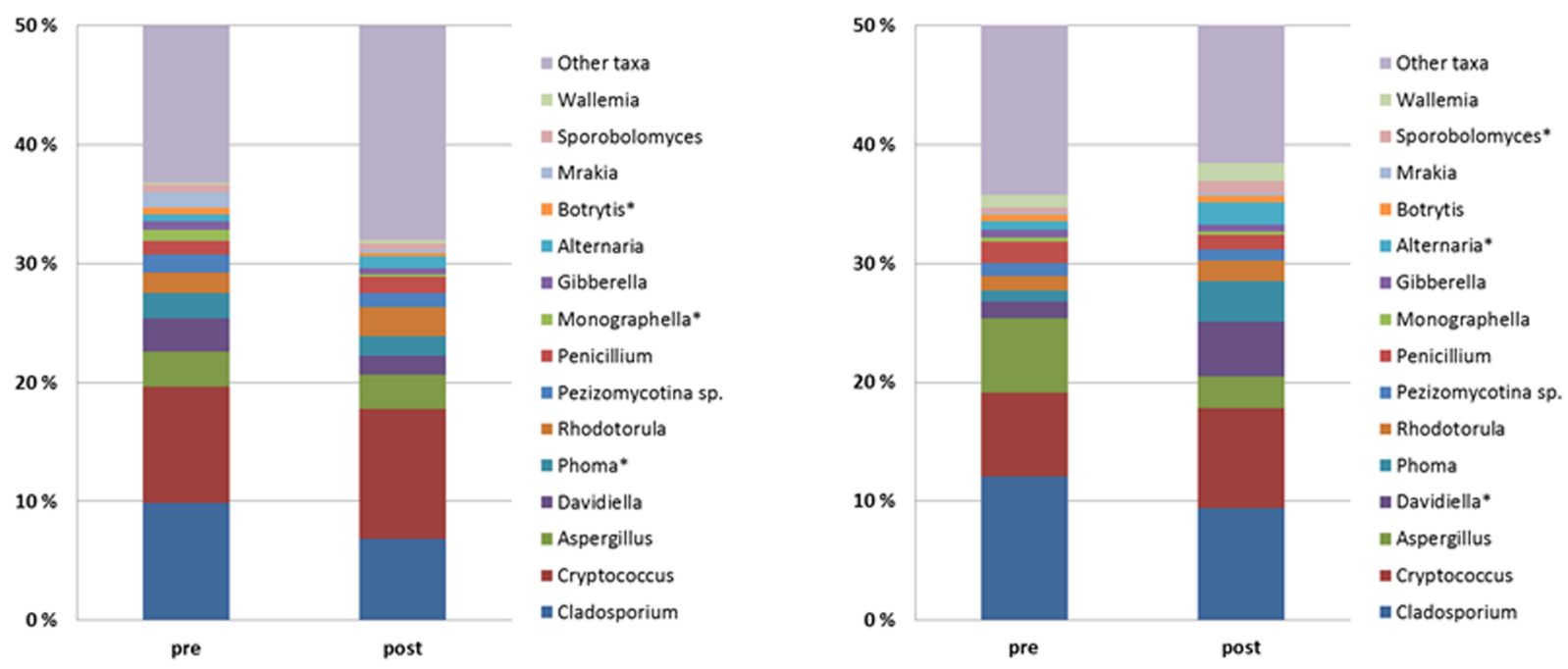

Fig. 1 Median relative abundance of the 15 top abundant bacterial $(\mathbf{a}, \mathbf{b})$ and fungal $(\mathbf{c}, \mathbf{d})$ genera in house dust of moisture-damaged homes: pre and post moisture damage renovations ( $20+20$ paired house dust samples; bacteria 1A, fungi 1C), and pre and post moisture damage interventions by moving into another house $(21+21$ paired house dust samples; bacteria 1B and fungi 1D). *Significant $(p<0.05)$ differences of relative abundance of taxa in pairwise sample comparison pre vs. post using Wilcoxon signed-rank test

weighted Unifrac distance (Table 3). Similarly, renovation had a small but significant impact on the fungal community composition as measured by the Binary Jaccard distance (Table 3). Figure 3 shows the bacterial and fungal communities pre and post moisture damage interventions.

\section{Identification of indicator taxa}

Bacterial and fungal taxa that were associated with moisture damage renovations in buildings were identified by applying various statistical approaches.

First we identified principal coordinates based on weighted bacterial Unifrac and fungal Bray-Curtis distance with Eigenvalues above 1 that associated with moisture damage renovations (Additional file 2: Table S7). PCoA1 for bacteria and PCoA7 for fungi were selected based on their associations. The 157 bacterial and 33 fungal OTUs, respectively, that correlated significantly $(p<0.05)$ and the strongest (Spearman rank-order Correlations rho $>|0.5|$ for bacteria and $>|0.4|$ for fungi) with those two axes were selected as potential indicator taxa (Additional file 2: Tables S8 and S9). For bacteria, almost all of these selected OTUs were reduced in relative abundance during moisture damage renovations and were largely allocated within the Actinomycetales order. For fungi, we 


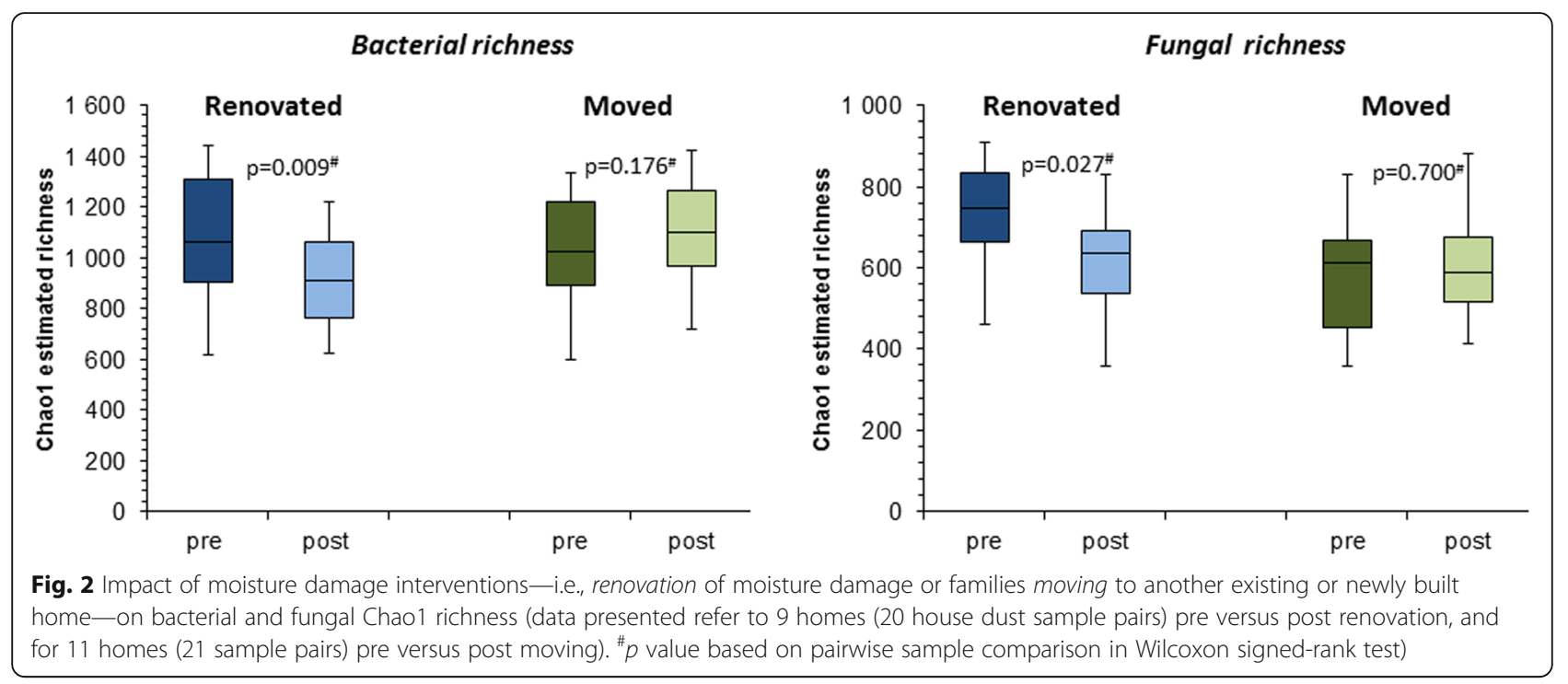

also observed mostly decreases in the relative abundance of the selected taxa.

Second, we performed indicator taxa analyses using LEfSe. Fifty-two bacterial and 10 fungal taxa were identified, applying the generally recommended criteria of $p$ value $<0.05$ and a LDA effect size $>2$ (Additional file 2: Tables S10 and S11). For bacteria, most of these OTUs were decreased in relative abundance during moisture damage renovations and were again frequently allocated to the Actinomycetales order. For fungi too, abundance of the identified taxa were more often reduced during moisture damage renovations; fungal taxa were allocated to various phylogenetic groups, mostly within the Ascomycota and Basidiomycota phyla.

Third, we applied glm-edgeR for the identification of indicator taxa, adjusting for sample type, season, pet keeping, the number of residents in the homes, and rural/urban location of the study homes. Applying a criterion of FDR corrected $p$ values $<0.1$, we identified 30 bacterial OTUs and 6 fungal indicator taxa with this approach (Additional file 2: Tables S12 and S13).
Finally, we created overlap tables for the bacterial and fungal taxa identified via the different approaches (Additional file 2: Tables S14 and S15) and selected the most promising candidate taxa based on their repeated detection via different approaches. For bacteria, we identified 27 OTUs that were picked up with at least two of the three methods (Table 4 and Additional file 2: Table S14). For fungi, none of the taxa were identified with more than one approach, resulting in a total of 49 taxa that were highlighted as potential moisture damage indicators (Additional file 2: Table S15). In order to confirm the validity of the taxa that were identified, we subsequently tested these 27 bacterial and 49 fungal candidate taxa individually in the HOTES dataset, exploring changes in their relative abundance and their association with moisture damage interventions, including renovation and in addition moving to a new home. Of the 27 bacterial OTUs tested, 25 showed significant $(p<0.05)$ associations with moisture damage renovations, all except a Staphylococcus OTU being reduced in relative abundance in house dust after renovation activities

Table 3 Impact of moisture damage interventions on weighted and unweighted bacterial and fungal beta-diversity (analyzed with ANOSIM). Results are shown for all interventions together (39 pre 41 post samples; note: two house dust samples collected in one home served as pre samples for both, renovation and moving, as part of the family moved, while the other part renovated the existing home) and for moisture damage renovations (20 sample pairs) and cases where families moved (21 sample pairs) separately

\begin{tabular}{|c|c|c|c|c|c|c|c|c|c|}
\hline \multirow[b]{3}{*}{ Study population } & \multirow[b]{3}{*}{$N_{\text {samples }}$} & \multicolumn{4}{|c|}{ Bacteria } & \multicolumn{4}{|l|}{ Fungi } \\
\hline & & \multicolumn{2}{|c|}{ Weighted Unifrac } & \multicolumn{2}{|c|}{ Unweighted Unifrac } & \multicolumn{2}{|c|}{ Bray-Curtis } & \multicolumn{2}{|c|}{ Binary Jaccard } \\
\hline & & $R$ & $p$ value & $R$ & $p$ value & $R$ & $p$ value & $R$ & $p$ value \\
\hline All home pre and post & $39+41$ & 0.043 & 0.018 & 0.024 & 0.060 & 0.008 & 0.233 & 0.015 & 0.137 \\
\hline Renovated homes pre and post & $20+20$ & 0.042 & 0.102 & 0.017 & 0.235 & -0.003 & 0.481 & 0.061 & 0.029 \\
\hline Homes where family moved pre and post & $21+21$ & 0.045 & 0.043 & 0.024 & 0.154 & 0.028 & 0.093 & 0.026 & 0.144 \\
\hline
\end{tabular}



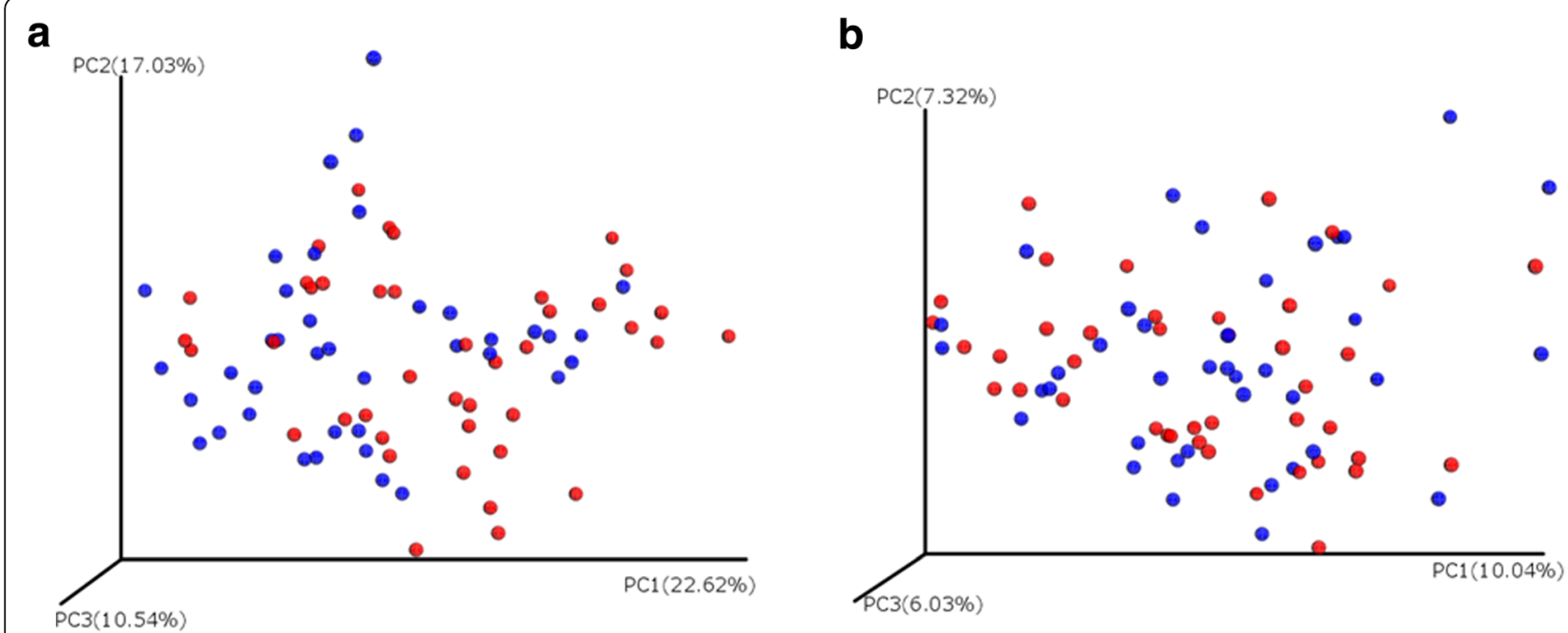

Fig. 3 Bacterial (a) and fungal (b) community composition (abundance weighted beta-diversity, PCoA plots) in house dust samples of moisturedamaged homes pre and post interventions (pre intervention: red; post: blue)

(Table 4). The majority of bacterial OTUs that associated with moisture damage renovations were allocated to various families within the Actinomycetales order, as highlighted in the phylogenetic tree in Fig. 4. Six of these OTUs were also associated with moving as the mean of moisture damage intervention (Table 4). For fungi, 11 of the 47 tested taxa were significantly $(p<0.05)$ associated with moisture damage renovations (nine reduced in relative abundance, two increased: Rhodotorula buffonii and Tremellaceae) (Table 5). Two of those taxa, Humicola nigrescens and Mortierella umbellata, showed also borderline significant $(p<0.1)$ association with moving.

\section{Evaluation of indicator taxa against varying degrees of moisture damage and visible mold in homes of the LUKAS cohort}

In the final step of our analyses, we aimed to test the suitability of using relative abundance data of the taxa identified in HOTES to predict moisture damage in buildings. For this purpose, we used living room floor dust microbiota data from the LUKAS cohort consisting of approximately 400 homes. We studied associations of the bacterial and fungal taxa that were identified in the HOTES study with three-level moisture damage and visible mold variables in the LUKAS homes.

Nine of the 25 bacterial OTUs identified in HOTES (Table 4) were not found in the LUKAS house dust dataset; eight OTUs showed tendencies $(p$ value $<0.1$ ) for an increase in relative abundance in house dust of homes with more severe moisture and/or mold damage (Additional file 2: Table S16). Of those, two OTUs-taxonomically allocated to Phycicoccus and Aeromicrobium taxa-were significantly ( $p$ value $<0.05$ ) associated with moisture and mold damage severity in LUKAS homes after correction for multiple testing (Table 6).

Three of the 11 fungal taxa identified in HOTES were not found in the LUKAS house dust dataset (Additional file 2: Table S17). Of the relative abundance of eight fungal taxa tested only one-that of Humicola nigrescens - was significantly associated with increasing moisture damage and mold severity ( $p$ values 0.014 and $<0.001$, respectively; Table 6 ). The association between the higher relative abundance of Aeromicrobium and Humicola nigrescens with the increasing severity of moisture damage and between higher relative abundance of Phycicoccus, Aeromicrobium, and Humicola nigrescens and the increasing severity of visible mold growth was independent of potential confounders as indicated by quantile regression analysis (Additional file 5: Figure S3).

\section{Discussion}

In this study, we utilized a cohort of severely moisture damaged homes to study the characteristics of house dust microbiota and observed a significant, though subtle, effect of viable microbial growth in building materials on the house dust microbiota composition in these homes. We followed a subsample of those homes through moisture damage renovations and showed individual microbial taxa, rather than overall community composition, to respond to these interventions. We see consistent responses mostly in bacterial taxa, specifically located in a cluster of families within the Actinomycetales order. Testing the potential usefulness of these taxa for indicating moisture problems in buildings in another, larger study, we find dose-response relationships in a number of taxa. 
Table 4 Bacterial taxa associated with moisture damage renovations, as determined via PCoA approach, LefSe, and glm-edgeR (presented are OTUs that were detected with at least two of the three approaches; arrows indicate decrease or increase in relative abundance during moisture damage renovations)

\begin{tabular}{|c|c|c|c|c|c|c|}
\hline OTU ID & Taxonomic allocation & & Weighted UniFrac & LefSe & glm-edgeR & \\
\hline a 826144 & Sphingobacteriaceae & Pedobacter & $x$ & $x$ & $x$ & \\
\hline a972343 & Nakamurellaceae & & $x$ & $x$ & & \\
\hline a,b 965853 & Solirubrobacterales & & $x$ & $x$ & & \\
\hline a,b939252 & Staphylococcaceae & Staphylococcus & $x$ & $x$ & & \\
\hline a 876170 & Microbacteriaceae & Salinibacterium & $x$ & $x$ & & \\
\hline a870223 & Nakamurellaceae & & $x$ & $x$ & & \\
\hline a 825183 & Chitinophagaceae & & $x$ & $x$ & & \\
\hline a 810959 & Intrasporangiaceae & Phycicoccus & $x$ & $x$ & & \\
\hline${ }^{a} 672144$ & Comamonadaceae & Roseateles & $x$ & $x$ & & \\
\hline${ }^{\mathrm{a}} 662915$ & Aurantimonadaceae & & $x$ & $x$ & & \\
\hline$a_{581286}$ & Microbacteriaceae & & $x$ & $x$ & & \\
\hline$a_{549557}$ & Nocardioidaceae & & $x$ & $x$ & & \\
\hline $\mathrm{a}, \mathrm{b} 538111$ & Intrasporangiaceae & & $x$ & $x$ & & \\
\hline${ }^{a} 4398116$ & Cellulomonadaceae & Actinotalea & $x$ & $x$ & & \\
\hline$a, b 367851$ & Propionibacteriaceae & Microlunatus & $x$ & $x$ & & \\
\hline$a_{324217}$ & Nocardioidaceae & Aeromicrobium & $x$ & $x$ & & \\
\hline 285591 & Solirubrobacterales & & $x$ & $x$ & & \\
\hline $\mathrm{a}, \mathrm{b} 279515$ & Intrasporangiaceae & Phycicoccus & $x$ & $x$ & & \\
\hline${ }^{\mathrm{a}} 207885$ & Burkholderiaceae & Burkholderia & & $x$ & $x$ & \\
\hline${ }^{\mathrm{a}} 196652$ & Burkholderiaceae & Burkholderia & & $x$ & $x$ & \\
\hline${ }^{\mathrm{a}} 134121$ & Microbacteriaceae & & $x$ & $x$ & & \\
\hline${ }^{a} 112867$ & Chloroflexi & Ellin6529 & $x$ & $x$ & & \\
\hline${ }^{a} 1105814$ & Bradyrhizobiaceae & & $x$ & $x$ & & \\
\hline${ }^{\mathrm{a}} 1079481$ & Pseudonocardiaceae & Pseudonocardia & $x$ & $x$ & & \\
\hline $\mathrm{a}, \mathrm{b} 1051744$ & Microbacteriaceae & & $x$ & $x$ & & \\
\hline 1039041 & Sporichthyaceae & & $x$ & $x$ & & \\
\hline${ }^{\mathrm{a}} 1033426$ & Nocardioidaceae & Nocardioides & $x$ & $x$ & & \\
\hline
\end{tabular}

${ }^{2}$ Statistically significant difference $(p<0.05$; Wilcoxon signed-rank test) in house dust pre versus post moisture damage renovation in pairwise sample comparison $(N=20+20)$

${ }^{\mathrm{b}}$ Statistically significant difference $(p<0.05$; Wilcoxon signed-rank test) in house dust samples pre versus post moving into a new home pairwise sample comparison $(N=21+21)$

One of the key findings of our current study is that moisture damage interventions neither appear to be linked to major changes in the most abundant bacterial and fungal taxa in house dust, nor to major changes in the overall community structure. While there were some statistically significant shifts in community composition, the effect size was small and more pronounced for bacteria. Likewise, looking at changes in relative abundance in the top 15 most abundant taxa between pre and post interventions, constituting close to $50 \%$ of bacterial and more than $50 \%$ fungal sequences, we observe little significant changes. In line with these findings, two earlier studies that have considered moisture damage indicators reported similarly non-significant or barely significant associations of the microbial community composition in house dust with observations of visible mold, and the absence of associations with observations of water leaks $[31,32]$. A very clear difference in both bacterial and fungal community composition in response to moisture damage was reported in a study that monitored previously flooded and non-flooded homes in Colorado [12]. It is clear that flooding represents a massive event, compared to a water leak or other moisture damage in a home. Given that the monitoring of those homes was conducted only 3 months after the flooding event, it is conceivable that the striking impact on the microbial composition in those buildings still persisted. 


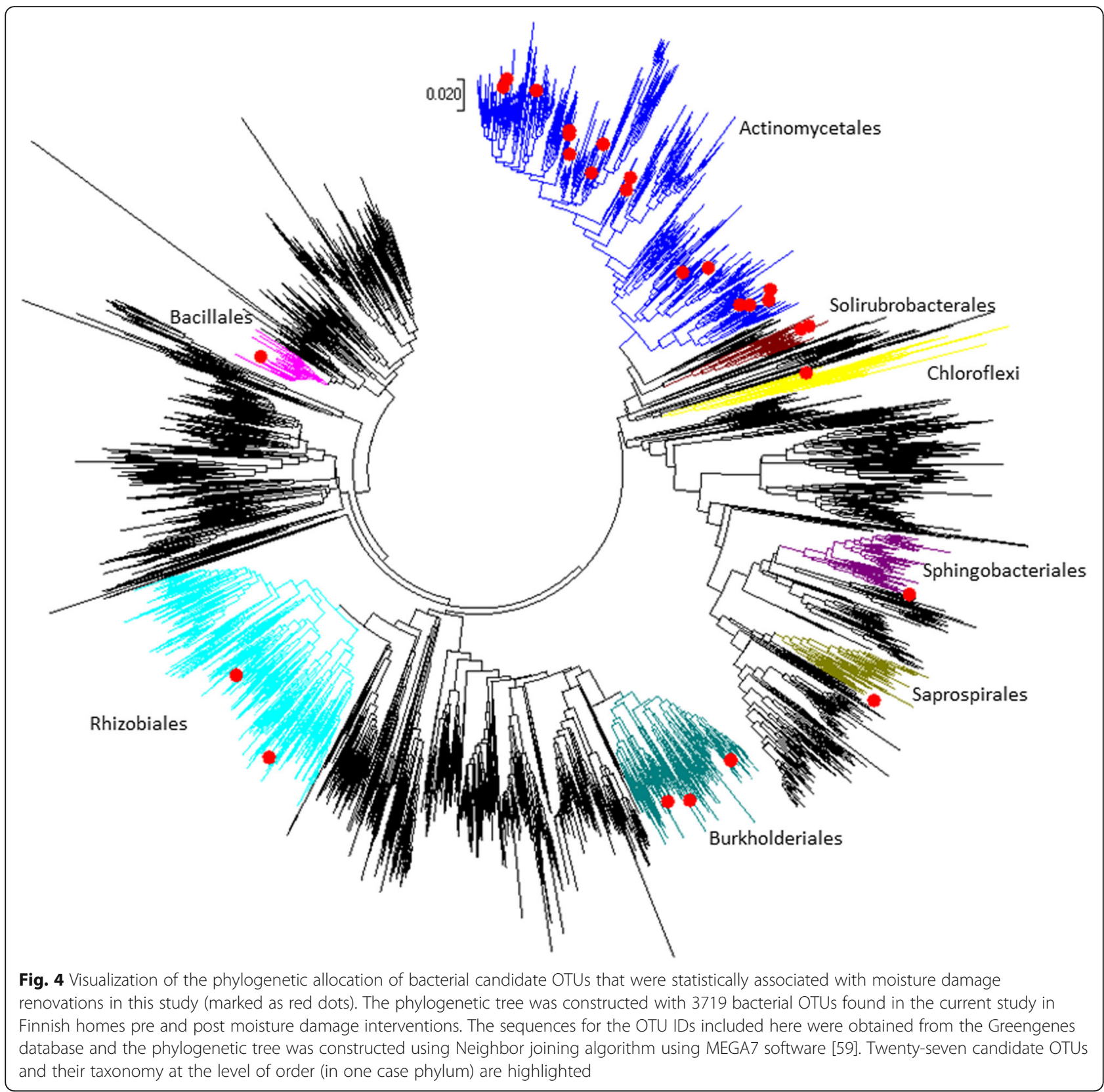

In spite of the absences of clear changes in community composition in our study, we did observe a significant reduction in both bacterial and fungal richness and diversity in house dust after renovation of moisture damage. Interestingly, we did not observe a similar effect in cases where people moved away from their old, damaged to a new or existing home. One could hypothesize that especially moving into an existing home would mean adding the microbiome associated with the family to the existing building microbiota, which could compensate for a loss in richness due to moving from a "wet" to a "dry" house. It is also possible that intensive cleaning following the renovation activities may account for the impact on reducing microbial richness in house dust reservoirs. However, an effective removal of moisturedamaged materials and the source of microbial growth could explain our observation. In other studies, higher fungal, but not bacterial richness has been reported for homes where water leaks had been observed compared to homes without such observations [31, 32].

Taken together, these findings suggest that the fungal and bacterial microbiota in house dust of moisturedamaged homes are not marked by a common and striking shift relative to dry homes but rather may experience more subtle changes in some of the lessabundant taxa. 
Table 5 Fungal taxa associated with moisture damage renovations, as identified via PCoA approach, LefSe, and glm-edgeR, and confirmed in pairwise sample comparison pre and post moisture damage renovations ( $p<0.05$ in Wilcoxon signed-rank test). Arrows indicate decrease or increase in relative abundance during moisture damage renovations

\begin{tabular}{|c|c|c|c|c|c|c|c|c|}
\hline \multicolumn{5}{|c|}{ Taxonomic allocation } & \multirow[t]{2}{*}{ Bray-Curtis distance } & \multirow[t]{2}{*}{ LefSe } & \multirow[t]{2}{*}{ glm-edgeR } & \\
\hline Phylum & Class & Family & Genus & Species & & & & \\
\hline Ascomycota & Taphrinomycetes & Taphrinaceae & Taphrina & padi & $x$ & & & \\
\hline Basidiomycota & Agaricomycetes & Meruliaceae & Bjerkandera & adusta & $x$ & & & \\
\hline Ascomycota & Sordariomycetes & Chaetomiaceae & Humicola & nigrescens & & $x$ & & \\
\hline Ascomycota & Dothideomycetes & Venturiaceae & Venturia & chlorospora & & $x$ & & \\
\hline Zygomycota & Incertaesedis & Mortierellaceae & Mortierella & umbellata & & $x$ & & \\
\hline Basidiomycota & Microbotryomycetes & Incertaesedis & Rhodotorula & buffonii & & $x$ & & \\
\hline Basidiomycota & Tremellomycetes & Tremellaceae & & & & $x$ & & \\
\hline Ascomycota & Sordariomycetes & Amphisphaeriaceae & Monographella & nivalis & & $x$ & & \\
\hline Ascomycota & Sordariomycetes & Nectriaceae & Nectria & ramulariae & & $x$ & & \\
\hline Basidiomycota & Agaricomycetes & Coniophoraceae & Coniophora & puteana & & & $x$ & \\
\hline Basidiomycota & Agaricomycetes & Polyporaceae & Trametes & versicolor & & & $x$ & \\
\hline
\end{tabular}

\section{The need to identify microbial signatures in} moisture-damaged residences

There are many reasons to try to identify and specify key microbial factors that are associated with moisture damage in buildings. For one, identifying these factors will allow more specific analyses of health effects upon exposure, ultimately aimed at improving our understanding of the mechanisms and causally involved agents underlying the well-established association between moisture damage in buildings and adverse health outcomes in building residents. So far, the evidence to confirm the general involvement of microbial exposure in adverse health effects in damp building has been inconclusive $[4,23,24,31]$. There is great need for objective measurements: (i) to support building inspections for moisture damage and dampness, as a diagnostic tool; (ii) for monitoring the microbial status of buildings, flagging conditions or changes in conditions that may be adverse to human health; and ideally (iii) for grading "severity" of moisture damage in the existing building stock. It is obvious that fixing all moisture damage in buildings immediately is an impossible task, given the estimates of 10 to $50 \%$ of the existing building stock being affected by some level of moisture damage $[2,3]$. Tools that

Table 6 Replication study in the LUKAS cohort: bacterial OTUs and fungal taxa identified in the HOTES study, with significant differences ( $p<0.05$; Kruskal-Wallis test after Bonferroni correction) in relative abundance in house dust of homes categorized by moisture damage severity and extent of visible mold in the LUKAS cohort (75th Pctl, 75th percentile; moisture damage: 0 ... no moisture damage, 1 ... minor moisture damage, $2 \ldots$ major moisture damage; visible mold: 0 ... no visible mold, 1 ... spots of visible mold, $2 \ldots$ visible mold; $N$, number of homes)

\begin{tabular}{|c|c|c|c|c|c|c|c|c|c|c|}
\hline \multirow[b]{3}{*}{ OTU ID } & \multirow{2}{*}{\multicolumn{2}{|c|}{ Taxonomy }} & & \multicolumn{3}{|c|}{ Moisture damage } & & \multicolumn{3}{|c|}{ Visible mold } \\
\hline & & & & \multirow[b]{2}{*}{ N } & \multicolumn{2}{|c|}{ Relative abundance } & \multirow[b]{2}{*}{$p$ value } & \multicolumn{3}{|c|}{ Relative abundance } \\
\hline & Family & Genus & Species & & Median & 75th Pctl & & $N$ & Median & 75th Pctl \\
\hline
\end{tabular}

Bacterial OTUs

324217 Nocardioidaceae Aeromicrobium

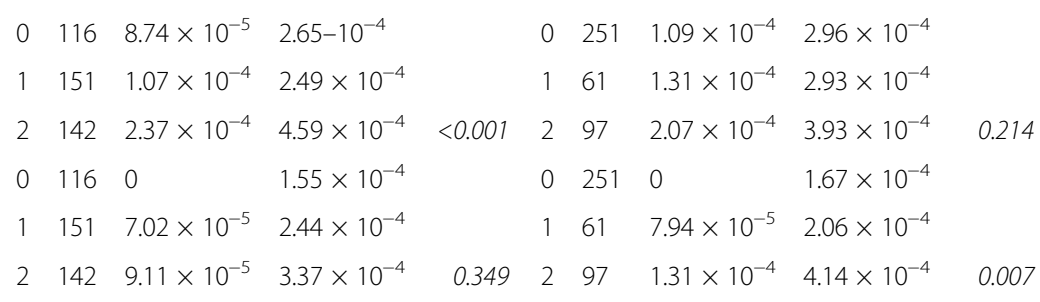

Fungal taxa

$\begin{array}{lllllllllllll}- & \text { Chaetomiaceae } \quad H u m i c o l a & \text { nigrescens } & 0 & 111 & 0 & 3.80 \times 10^{-4} & & 0 & 247 & 0 & 5.28 \times 10^{-4} & \\ & & & 1 & 149 & 5.28 \times 10^{-5} & 6.31 \times 10^{-4} & & 1 & 56 & 5.97 \times 10^{-5} & 4.49 \times 10^{-4} & \\ & & & 2 & 136 & 2.45 \times 10^{-4} & 8.82 \times 10^{-4} & 0.014 & 2 & 93 & 3.57 \times 10^{-4} & 1.22 \times 10^{-3} & <0.001\end{array}$


would separate severe-as in more health hazardous-from less-severe moisture damage would allow prioritizing remediation efforts. Microbial measurements could support answering the needs listed here, in contributing to a holistic building assessment approach. Novel sequencing-based technology allows for a characterization of microbiota in samples with high resolution, not restricted to the fraction of taxa that can be cultivated under standard laboratory conditions. There is hope that novel, sequencing-based technologies could complement and strengthen microbial determinations in building assessments, which to date still mostly rely on cultivation technique. Thus, a major objective of this current study was to make a first step towards closing this gap, by trying to identify "signatures of moisture damage" in house dust microbiota.

\section{Particular taxa as indicators of moisture damage}

We set out to address our goal by following severely moisture-damaged homes through moisture damage renovations and by screening for taxa that would be significantly reduced in relative abundance during these renovations. In examining the 15 most abundant genera (Fig. 2), the only significant change that we observed for bacteria was an increase of the human skin-associated bacterial taxon Staphylococcus in the post-renovation situation. For fungi, we did observe significant reductions in relative abundance of some of the more abundant genera during moisture damage renovations, namely Phoma, Botrytis, and Monographella. All three of these fungal genera are largely described in the context of being saprophytic or plant pathogenic taxa. Phoma has been noted in moisture-damaged buildings [9, 34, 35, 63], although it has also been detected in non-damaged buildings [63, 64]. Botrytis has only occasionally been reported in samples of indoor air $[65,66]$ and house dust of moisture-damaged buildings pre and post intervention [35]. This fungal genus is absent or only very rarely detected in samples of moisturedamaged building materials $[7,8]$, but it does have potential to proliferate on gypsum board [67]. We are not aware of reports of Monographella in indoor samples, except for a mentioning of the detection of Microdochium, its telemorph, in house dust of a moisturedamaged building [35].

In looking at the community as a whole rather than the most abundant taxa, we applied various methods to try to identify indicator taxa. For bacteria, we identified 25 OTUs that were picked-up by at least two of the three approaches applied and that were confirmed to be significantly associated with moisture damage renovations when tested individually using pairwise sample comparisons. The majority of these OTUs clustered within a number of families within the Actinomycetales order, such as Nakamurellaceae, Intrasporangiaceae, and Nocardiaceae, which include spore-forming, filamentousgrowing taxa. Based on cultivation studies, the presence of actinobacteria in samples of indoor air and building materials has been proposed to be indicative of moisture problems in Finnish buildings [19]; the reference here is specifically to spore-forming, filamentous actinomycetes type actinobacteria, morphologically recognizable under the microscope. Also other studies have reported the presence of such bacterial taxa in moisture- and mold-damaged building materials $[7,20,68-70]$. Thus, both cultivation and cultivation-independent techniques indicate that representatives of Actinomycetales may be important components of moisture-damaged buildings.

The indicator taxa analysis for fungi did show much less clear patterns compared to the bacterial analysis. This was in spite of the fact that we were able to observe an impact of viable fungal growth in building materials on the mycobiota composition in house dust. The absence of clear fungal signals is striking because conditions of moisture damage, dampness, and indoor mold are in particular considered a fungal phenomenon, even if the relevance of bacteria in these conditions has been well recognized [9]. Based on this study, it appears to be more challenging with the current methods and their strengths and limitations to identify fungal than bacterial taxa in house dust that are associated with moisture conditions and microbial growth on and in building structures. Future studies should consider coupling house dust investigations with sequencing of moisture-damaged materials in the respective buildings, which could facilitate a more thorough search for indicator taxa.

In a replication study, utilizing house dust samples of over 400 Finnish homes that have been thoroughly inspected for observations of moisture damage and visible mold, two of the bacterial and one of the fungal potential indicator taxa were found to be associated significantly with severity of the dampness observations in these homes. Those were bacterial OTUs taxonomically allocated to Phycicoccus and Aeromicrobium, and the fungal species Humicola nicgrescens. None of these candidates have earlier been specifically named and linked to moisture conditions in buildings, but they have been isolated from different environmental samples. However, both of the bacterial candidates are actinobacteria and belong to the Actinomycetales order, which again links to the earlier notion that these sequencing-based findings appear to complement cultivation-based knowledge on the link of certain groups of actinomycetes with damp buildings. Humicola is a mostly soil-associated fungus, but has been reported occasionally in indoor samples $[66,71,72]$. All of the identified taxa are rare sequence types, representing typically less than $0.1 \%$ 
of sequences in the house dust samples. This low abundance at least challenges the usefulness of these specific taxa in analyses against health outcomes in the search of causally involved agents. The potential value of these candidate taxa will likely be restricted to their use as moisture damage indicators, contributing to a list of "moisture damage signatures" that may be defined with support of other sequencing studies in the future. Such effort could be considered the next generation of moisture damage indicator microbes, expanding the list that has been proposed in 1994 by Samson and colleagues in the era of cultivation [6] towards the use of DNA-based measurement approaches.

The limited number of homes and samples in this original moisture damage intervention study restricts broad conclusions on the identified microbial peculiarities and signatures of moisture damage. Samples of settled dust and floor dust were used as sample materials to analyze changes in the indoor microbiota following moisture damage interventions. We acknowledge that house dust samples have limitations in how well they reflect airborne exposures and potentially also in how well they reflect moisture conditions and changes of such conditions in buildings. A clear strength is the intervention design that was utilized to highlight potential moisture damage indicators. It is well known from studies of the built environment that the indoor microbiota are affected by and shaped by a multitude of factors relating to the outdoor environment, building characteristics and use, and occupants and their behavior [9, 73]. Thus, monitoring the same homes or at least the same families occupying homes in pre versus post intervention comparisons is powerful. Moreover, the candidate taxa of our study were in part replicated in a large cohort of homes with varying degrees of moisture damage. However, both of these studies were geographically restricted to Finland, its climatic, building and other specificities. Future studies carried out in other countries and climates will need to determine whether the findings of this study have wider implications in terms of their applicability to moisture damage conditions more broadly.

\section{Conclusions}

This is one of the first studies to use culture-independent, high throughput sequencing to investigate the fungal and bacterial microbiota of severely moisture-damaged homes in a pre- versus post-renovation follow-up. We find that the impact of the intervention on microbial exposures for the occupants overall was subtle, and we recognize that more work remains to be done in order to support a quantitative and qualitative measurement of moisture damage using DNA-based approaches. However, several findings of this study should support future inquiries on the association between indoor microbiota and moisture damage using sequencing methods. For one, findings showed that richness decreased significantly during renovations, indicating that the number of different microbial taxa may be an important component of indoor exposures to consider, also in the context of moisture damage. Two, for bacteria we observed a clear concentration of moisture damage renovation associated taxa within the order Actinomycetales, which may provide a more focused target for future damp-building-related studies. Finally, this study demonstrates the utility of comparing pre and post intervention homes as a strategy for identifying moisture damage-associated microbial exposures.

\section{Addtional files}

Additional file 1: The Lukas cohort; Microbiota of different types of house dust in moisture damaged homes; References. (DOC 33 kb)

Additional file 2: Table S1 to S17. Detailed table legends are provided in the individual excel sheets. (XLSX 139 kb)

Additional file 3: Figure S1. Mean relative abundance of the top 15 bacterial (A) and fungal (B) genera in dust samples from 41 moisture damage residences (floor dust living room (FDLR), floor dust form other rooms with moisture damage (FDOR), airborne settled dust (SD)). (TIFF 100 kb)

Additional file 4: Figure S2. Categorization of moisture damaged homes based on low (blue), medium (yellow) and high (red) fungal viable growth on building materials and impact on fungal Bray-Curtis-based beta-diversity in house dust of these homes. (PDF $10 \mathrm{~kb}$ )

Additional file 5: Figure S3. Regression coefficient plots for the slope of the relationship between OTU relative abundance and increasing severity of moisture damage or visible mold. The shaded areas enclose the $95 \%$ confidence interval and where the lower limit is above the 0-line the quantile of the OTU relative abundance is significantly higher in homes with higher damage/mold severity classification. Quantiles from the 50th (median) to 95th are presented; the confidence intervals were calculated with 0.05 quantile intervals using 200 permutations. Panel A-C, moisture damage; panel D-F, visible mold. Aeromicrobium sp. OTU (A,D); Phycicoccus sp. OTU (B,E); Humicola nigrescens (C,F). (TIFF $125 \mathrm{~kb}$ )

\section{Acknowledgements}

The authors want to thank all the families participating in this research. We acknowledge the great support of the Organization of Respiratory Health, Finland, in organizing the homeloukku study, performing building inspections, recruiting of study homes and sample collection. The research analysts at THL's Environmental Health Unit, Katja Saarnio, Mervi Ojala, and Heli Martikainen, as well as researchers Kaisa Jalkanen and Pauli Tuoresmäki, are acknowledged for excellent laboratory work and statistical support. We also wish to thank Emeritus professor Aino Nevalainen, who has been a leader in moisture damage research for several decades and who has also been the driving force behind making the HOTES study happen.

\section{Availability of data and materials}

The bacterial and fungal sequences were submitted in NCBI Sequence Read Archive (SRA) under the Bioproject ID PRJNA399233 with the following BioSample numbers: SAMN07624174-SAMN07624327 for bacterial and SAMN007624555-SAMN07624708 for fungal data. An analysis script for the sequence processing is available in GitHub under https://github.com/ balaphd/HOTES-analysis. The metadata file used in these analyses is supplemented in Additional file 2: Table S1. 


\section{Authors' contributions}

$\mathrm{MT}, \mathrm{AH}, \mathrm{JP}, \mathrm{BJ}, \mathrm{RIA}, \mathrm{PK}$, and AK designed the research. $\mathrm{KJ}$ was key responsible for conducting the field work, sample and data collection. MV and MT supervised laboratory processes including sample processing, extraction and DNA-based analyses and performed calculation of qPCR data. MS supervised laboratory analyses and produced the microbial toxin data and interpretation. $\mathrm{BJ}$ and RIA performed the sequence data processing, bioinformatics, and statistical analyses of the sequencing data and share the first authorship. AV is data manager in both studies; AV and PK performed statistical analyses in the HOTES and LUKAS datasets, respectively. AK and JP supervised the statistical analyses. MT, RIA, and BJ wrote the manuscript. All authors read, edited, and approved the final manuscript.

\section{Funding}

This work was financially supported by the Academy of Finland (grant numbers 252718 and 296587), the Organization for Respiratory Health in Finland, Hengityssairauksien tutkimussäätiö, Juho Vainio Foundation (grant numbers 201310268), Ministry of Social Affairs and Health (2011-2013). The $\mathrm{PhD}$ project of Balamuralikrishna Jayaprakash is supported by Jenny ja Antti Wihurin Rahasto, Otto A. Malm donation fund, Kerttu ja Kalle Viikin rahasto, and Kuopion Seudun Hengityssäätiö. Rachel Adams was supported by the Alfred P. Sloan Foundation and the California Department of Public Health. The funding organizations were not involved in the design of the study and the collection, analysis, and interpretation of data or in writing the manuscript.

\section{Ethics approval and consent to participate}

Not applicable, no animal or human data were used in the current manuscript. Ethical clearance has, however, been applied for within the frameworks of the individual studies. Ethical approval for the HOTES and the LUKAS studies has been provided by the research ethics committee of the Hospital District of Northern Savo, Kuopio, Finland (decision 112/2006 Homeloukku, 33/2002 LUKAS1, 48/2004 LUKAS2).

\section{Consent for publication}

Not applicable

\section{Competing interests}

The authors declare that they have no competing interests.

\section{Publisher's Note}

Springer Nature remains neutral with regard to jurisdictional claims in published maps and institutional affiliations.

\section{Author details}

'Environmental Health Unit, National Institute for Health and Welfare, Kuopio, Finland. ${ }^{2}$ Plant and Microbial Biology, University of California, Berkeley, California, USA. ${ }^{3}$ California Department of Public Health, Richmond, California, USA. ${ }^{4}$ School of Engineering, Aalto University, Espoo, Finland. ${ }^{5}$ Department for Agrobiotechnology (IFA-Tulln), University of Natural Resources and Life Sciences, (BOKU), Vienna, Tulln, Austria. ${ }^{6}$ Department of Public Health, Helsinki University, Helsinki, Finland.

Received: 25 May 2017 Accepted: 27 September 2017

\section{Published online: 13 October 2017}

\section{References}

1. Fisk WJ, Lei-Gomez Q, Mendell MJ. Meta-analyses of the associations of respiratory health effects with dampness and mold in homes. Indoor Air. 2007;17(4):284-96.

2. IOM (Institute of Medicine). Damp indoor spaces and health. Washington D. C: The National Academic Press; 2004

3. WHO Regional Office for Europe. WHO guidelines for indoor air quality: dampness and mould. Copenhagen: WHO Regional Office for Europe; 2009.

4. Mendell MJ, Mirer AG, Cheung K, Douwes J. Respiratory and allergic health effects of dampness, mold, and dampness-related agents: a review of the epidemiologic evidence. Environ Health Perspect. 2011;119(6):748-56.

5. Kanchongkittiphon W, Mendell MJ, Gaffin JM, Wang G, Phipatanakul W. Indoor environmental exposures and exacerbation of asthma: an update to the 2000 review by the Institute of Medicine. Environ Health Perspect. 2015;123:6-20.
6. Samson RA, Flannigan B, Flannigan M, Verhoeff A, Adan O, Hoekstra E. Health implications of fungi in indoor environments. Amsterdam: Elsevier; 1994

7. Hyvärinen A, Meklin T, Vepsäläinen A, Nevalainen A. Fungi and actinobacteria in moisture-damaged building materials-concentrations and diversity. Int Biodeterior Biodegrad. 2002;49:27-37.

8. Andersen B, Frisvad JC, Sondergaard I, Rasmussen IS, Larsen LS. Associations between fungal species and water-damaged building materials. Appl Environ Microbiol. 2011;77:4180-8.

9. Nevalainen A, Täubel M, Hyvärinen A. Indoor fungi: companions and contaminants. Indoor Air. 2015;25:125-56.

10. Cho SJ, Cox-Ganser JM, Park JH. Observational scores of dampness and mold associated with measurements of microbial agents and moisture in three public schools. Indoor Air. 2016;26:168-78.

11. Dharmage S, Bailey M, Raven J, Mitakakis T, Thien F, Forbes A, Guest D, Abramson M, Walters E. Prevalence and residential determinants of fungi within homes in Melbourne, Australia. Clin Exp Allergy. 1999;29: 1481-9.

12. Emerson JB, Keady PB, Brewer TE, Clements N, Morgan EE, Awerbuch J, Miller SL, Fierer N. Impacts of flood damage on airborne bacteria and fungi in homes after the 2013 Colorado front range flood. Environ Sci Tech. 2015;49:2675-84.

13. Hunter C, Grant C, Flannigan B, Bravery A. Mould in buildings: the air spora of domestic dwellings. Int Biodeterior. 1988;24:81-101.

14. Hyvärinen A, Reponen T, Husman T, Nevalainen A. Comparison of the indoor air quality in mould damaged and reference buildings in a subarctic climate. Cent Eur J Public Health. 2001;9:133-9.

15. Purokivi MK, Hirvonen MR, Randell JT, Roponen MH, Meklin TM, Nevalainen AL, Husman TM, Tukiainen HO. Changes in pro-inflammatory cytokines in association with exposure to moisture-damaged building microbes. Eur Respir J. 2001;18:951-8.

16. Reponen $T$, Singh $U$, Schaffer $C$, Vesper S, Johansson E, Adhikari A, Grinshpun SA, Indugula R, Ryan P, Levin L. Visually observed mold and moldy odor versus quantitatively measured microbial exposure in homes. Sci Total Environ. 2010;408:5565-74

17. Sordillo JE, Alwis UK, Hoffman E, Gold DR, Milton DK. Home characteristics as predictors of bacterial and fungal microbial biomarkers in house dust. Environ Health Perspect. 2011;119(2):189-95.

18. Ren $P$, Jankun $T$, Belanger $K$, Bracken $M$, Leaderer $B$. The relation between fungal propagules in indoor air and home characteristics. Allergy. 2001;56:419-24

19. Nevalainen A, Pasanen A, Niininen M, Reponen T, Kalliokoski P, Jantunen M. The indoor air quality in Finnish homes with mold problems. Environ Int. 1991;17:299-302.

20. Pessi AM, Suonketo J, Pentti M, Kurkilahti M, Peltola K, Rantio-Lehtimaki A. Microbial growth inside insulated external walls as an indoor air biocontamination source. Appl Environ Microbiol. 2002;68:963-7.

21. Miller JD, Haisley PD, Reinhardt JH. Air sampling results in relation to extent of fungal colonization of building materials in some water-damaged buildings. Indoor Air. 2000;10:146-51.

22. Dharmage S, Bailey M, Raven J, Mitakakis T, Cheng A, Guest D, Rolland J, Forbes A, Thien F, Abramson M. Current indoor allergen levels of fungi and cats, but not house dust mites, influence allergy and asthma in adults with high dust mite exposure. Am J Respir Crit Care Med. 2001:164(1):65-71.

23. Holst G, Høst A, Doekes G, Meyer H, Madsen A, Plesner K, Sigsgaard T. Allergy and respiratory health effects of dampness and dampness-related agents in schools and homes: a cross-sectional study in Danish pupils. Indoor Air. 2016:26(6):880-91.

24. Jacobs J, Borras-Santos A, Krop E, Taubel M, Leppanen H, HaverinenShaughnessy U, Pekkanen J, Hyvarinen A, Doekes G, Zock JP, Heederik D. Dampness, bacterial and fungal components in dust in primary schools and respiratory health in schoolchildren across Europe. Occup Environ Med. 2014;71:704-12

25. Klanova K. The concentrations of mixed populations of fungi in indoor air: rooms with and without mould problems; rooms with and without health complaints. Cent Eur J Public Health. 2000;8:59-61.

26. Simoni M, Cai G, Norback D, Annesi-Maesano I, Lavaud F, Sigsgaard T, Wieslander G, Nystad W, Canciani M, Viegi G. Total viable molds and fungal DNA in classrooms and association with respiratory health and pulmonary function of European schoolchildren. Ped Allerg Immunol. 2001;22:843-52. 
27. Haugland R, Vesper S, Wymer L. Quantitative measurement of Stachybotrys chartarum conidia using real time detection of PCR products with the TaqMan TM fluorogenic probe system. Mol Cell Probes. 1999:13:329-40.

28. Haugland R, Vesper S. Method of identifying and quantifying specific fung and bacteria. US: Patent 6387652 B1; 2002.

29. Vesper S, McKinstry C, Haugland R, Wymer L, Bradham K, Ashley P, Cox D, Dewalt G, Friedman W. Development of an environmental relative moldiness index for US homes. J Occup Environ Med. 2007;49:829-33.

30. Ciaccio CE, Barnes C, Kennedy K, Chan M, Portnoy J, Rosenwasser L. Home dust microbiota is disordered in homes of low-income asthmatic children. J Asthma. 2015;52:873-80.

31. Dannemiller KC, Mendell MJ, Macher JM, Kumagai K, Bradman A, Holland N, Harley K, Eskenazi B, Peccia J. Next-generation DNA sequencing reveals that low fungal diversity in house dust is associated with childhood asthma development. Indoor Air. 2014;24:236-47.

32. Dannemiller KC, Gent JF, Leaderer BP, Peccia J. Influence of housing characteristics on bacterial and fungal communities in homes of asthmatic children. Indoor Air. 2016;26:179-92.

33. Green BJ, Lemons AR, Park Y, Cox-Ganser JM, Park J. Assessment of fungal diversity in a water-damaged office building. J Occup Environ Hyg. 2017;14:285-93.

34. Kettleson EM, Adhikari A, Vesper S, Coombs K, Indugula R, Reponen T. Key determinants of the fungal and bacterial microbiomes in homes. Environ Res. 2015;138:130-5.

35. Pitkäranta M, Meklin T, Hyvärinen A, Nevalainen A, Paulin L, Auvinen P, Lignell $\mathrm{U}$, Rintala $\mathrm{H}$. Molecular profiling of fungal communities in moisture damaged buildings before and after remediation-a comparison of culture-dependent and culture-independent methods. BMC Microbiol. 2011;11:235.

36. Hyvärinen A, Roponen M, Tiittanen P, Laitinen S, Nevalainen A, Pekkanen. Dust sampling methods for endotoxin - an essential, but underestimated issue. Indoor Air. 2006;16:20-7.

37. Kärkkäinen PM, Valkonen M, Hyvärinen A, Nevalainen A, Rintala H. Determination of bacterial load in house dust using qPCR, chemical markers and culture. J Enviro Monit. 2010;12:759-68.

38. Haugland RA, Siefring SC, Wymer LJ, Brenner KP, Dufour AP. Comparison of Enterococcus measurements in freshwater at two recreational beaches by quantitative polymerase chain reaction and membrane filter culture analysis. Water Res. 2005:39:559-68.

39. Täubel M, Karvonen AM, Reponen T, Hyvarinen A, Vesper S, Pekkanen J. Application of the environmental relative moldiness index in Finland. Appl Environ Microbiol. 2015:82:578-84.

40. Haugland RA, Varma M, Wymer LJ, Vesper SJ. Quantitative PCR analysis of selected Aspergillus, Penicillium and Paecilomyces species. Syst Appl Microbiol. 2004;27:198-210.

41. Vishwanath V, Sulyok M, Labuda R, Bicker W, Krska. Simultaneous determination of 186 fungal and bacterial metabolites in indoor matrices by liquid chromatography/tandem mass spectrometry. Anal. Bioanal. Chem 2009;395:1355-72.

42. Herlemann DP, Labrenz M, Jurgens K, Bertilsson S, Waniek JJ, Andersson AF. Transitions in bacterial communities along the $2000 \mathrm{~km}$ salinity gradient of the Baltic Sea. ISME J. 2011:5:1571-9.

43. Andersson AF, Lindberg M, Jakobsson H, Backhed F, Nyre P, Engstrand L. Comparative analysis of human gut microbiota by Barcoded pyrosequencing. PLoS One. 2008;3(7):e2836. https://doi.org/10.1371/journal. pone.0002836

44. Caporaso JG, Lauber CL, Walters WA, Berg-Lyons D, Lozupone CA Turnbaugh PJ, Fierer N, Knight R. Global patterns of $16 \mathrm{~S}$ rRNA diversity at a depth of millions of sequences per sample. Proc Natl Acad Sci U S A. 2011; 108(1):4516-22.

45. Smith DP, Peay KG. Sequence depth, not PCR replication, improves ecological inference from next generation DNA sequencing. PLoS One. 2014;9:e90234

46. Caporaso JG, Kuczynski J, Stombaugh J, Bittinger K, Bushman FD, Costello EK, Fierer N, Pena AG, Goodrich JK, Gordon JI. QIIME allows analysis of high-throughput community sequencing data. Nat Methods. 2010;7:335-6.

47. Martin M. Cutadapt removes adapter sequences from high-throughput sequencing reads. EMB Net J. 2010;17:10-2.

48. Bolger AM, Lohse M, Usadel B. Trimmomatic: a flexible trimmer for Illumina sequence data. Bioinformatics. 2014;30:2114-20.
49. Magoc T, Salzberg SL. FLASH: fast length adjustment of short reads to improve genome assemblies. Bioinformatics. 2011;27:2957-63.

50. Edgar RC, Haas BJ, Clemente JC, Quince C, Knight R. UCHIME improves sensitivity and speed of chimera detection. Bioinformatics. 2011:27:2194-200.

51. Edgar RC. Search and clustering orders of magnitude faster than BLAST. Bioinformatics. 2010;26:2460-1.

52. Caporaso JG, Bittinger K, Bushman FD, DeSantis TZ, Andersen GL, Knight R. PYNAST: a flexible tool for aligning sequences to a template alignment. Bioinformatics. 2010;26:266-7.

53. DeSantis TZ, Hugenholtz P, Larsen N, Rojas M, Brodie EL, Keller K, Huber T, Dalevi D, Hu P, Andersen GL. Greengenes, a chimera-checked 16S rRNA gene database and workbench compatible with ARB. Appl Environ Microbiol. 2006;72:5069-72

54. Dannemiller KC, Reeves D, Bibby K, Yamamoto N, Peccia J. Fungal high-throughput taxonomic identification tool for use with next-generation sequencing (FHiTINGS). J Basic Microbiol. 2014;54:315-21.

55. Wang Q, Garrity GM, Tiedje JM, Cole JR. Naive Bayesian classifier for rapid assignment of rRNA sequences into the new bacterial taxonomy. Appl Environ Microbiol. 2007;73:5261-7.

56. Lozupone C, Knight R. UniFrac: a new phylogenetic method for comparing microbial communities. Appl Environ Microbiol. 2005;71:8228-35.

57. Wickham H. Ggplot2: elegant graphics for data analysis: New York: Springer; 2016

58. R Team. R: a language and environment for statistical computing (version 3. 0. 2). Vienna: R Foundation for Statistical Computing; 2014.

59. Kumar S, Stecher G, Tamura K. MEGA7: molecular evolutionary genetics analysis version 7.0 for bigger datasets. Mol. Biol. Evolution. 2016;33:1870-4.

60. Karvonen AM, Hyvärinen A, Roponen M, Hoffmann M, Korppi M, Remes S, von Mutius E, Nevalainen A, Pekkanen J. Confirmed moisture damage at home, respiratory symptoms and atopy in early life: a birth-cohort study. Pediatrics. 2009;124(2):e329-38.

61. Segata N, Izard J, Waldron L, Gevers D, Miropolsky L, Garrett WS, et al. 2011. Metagenomic biomarker discovery and explanation. Genome Biol. 2011;12(6):1.

62. Robinson MD, McCarthy DJ, Smyth GK. edgeR: a bioconductor package for differential expression analysis of digital gene expression data. Bioinformatics. 2010;26(1):139-40.

63. Hyvärinen A. Characterizing moisture damaged buildings: environmental and biological monitoring: Ph.D. thesis. Kuopio: National Public Health Institute; 2002

64. Adams Rl, Amend AS, Taylor JW, Bruns TD. A unique signal distorts the perception of species richness and composition in high-throughput sequencing surveys of microbial communities: a case study of fungi in indoor dust. Microb Ecol. 2013;66:735-41.

65. Garrett MH, Rayment PR, Hooper MA, Abramson MJ, Hooper BM. Indoor airborne fungal spores, house dampness and associations with environmental factors and respiratory health in children. Clin Exp Allergy. 1998;28:459-67.

66. Shelton BG, Kirkland KH, Flanders WD, Morris GK. Profiles of airborne fungi in buildings and outdoor environments in the United States. Appl Environ Microbiol. 2002;68:1743-53.

67. Madsen AM. Effects of airflow and changing humidity on the aerosolization of respirable fungal fragments and conidia of Botrytis Cinerea. Appl Environ Microbiol. 2012;78:3999-4007.

68. Andersson MA, Nikulin M, Koljalg U, Andersson MC, Rainey F, Reijula K, Hintikka EL, Salkinoja-Salonen M. Bacteria, molds, and toxins in water-damaged building materials. Appl Environ Microbiol. 1997;63:387-93.

69. Rautiala S, Reponen T, Hyvärinen A, Nevalainen A, Husman T, Vehviläinen A, Kalliokoski P. Exposure to airborne microbes during the repair of moldy buildings. Am Ind Hyg Assoc J. 1996;57(3):279-84.

70. Rintala $H$, Nevalainen A, Suutari M. Diversity of streptomycetes in water damaged building materials based on 165 rDNA sequences. Lett Appl Microbiol. 2002;34:439-43.

71. Scott JA. Studies on indoor fungi: Ph.D. thesis. Toronto: Department of Botany, University of Toronto; 2001.

72. Wang X, Houbraken J, Groenewald J, Meijer M, Andersen B, Nielsen K, Crous P, Samson R. Diversity and taxonomy of Chaetomium and chaetomium-like fungi from indoor environments. Stud Mycol. 2016;84:145-224.

73. Prussin AJ, Marr LC. Sources of airborne microorganisms in the built environment. Microbiome. 2015;3:78. 